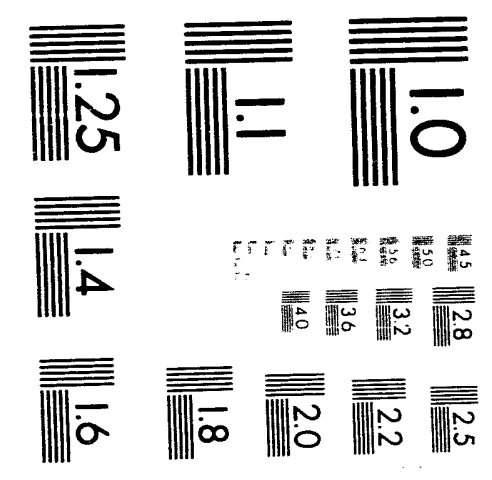



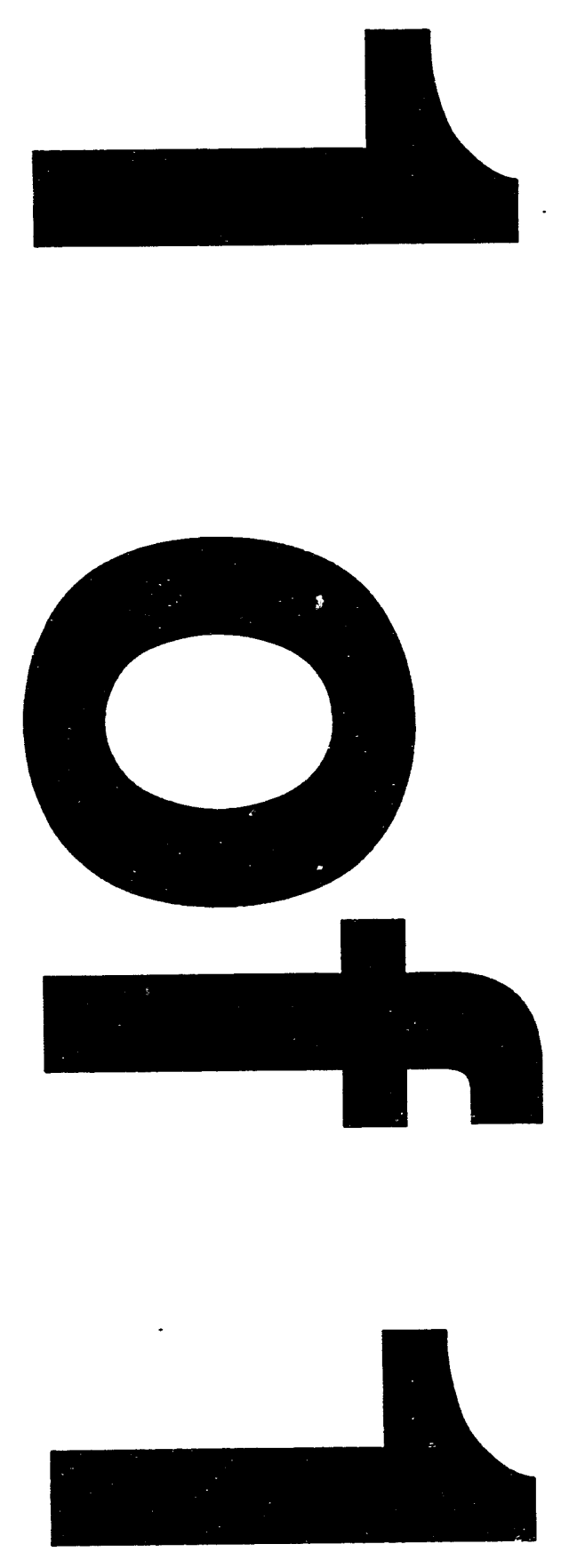


$$
\cos -931117-1
$$

UCRL-JC-115085

PREPRINT

\section{Evaluation of the Atmospheric Release Advisory Capability Emergency Response Model for Explosive Sources}

Ronald L. Baskett

Robert P. Freis

John S. Nasstrom

\section{TECEIVED \\ PIOY 191993 \\ OSTI}

This paper was prepared for submittal to the

Twentieth International Technical Meeting

on Air Modeling and Its Applications

Valencia, Spain

November 29-December 3, 1993

October 7, 1993

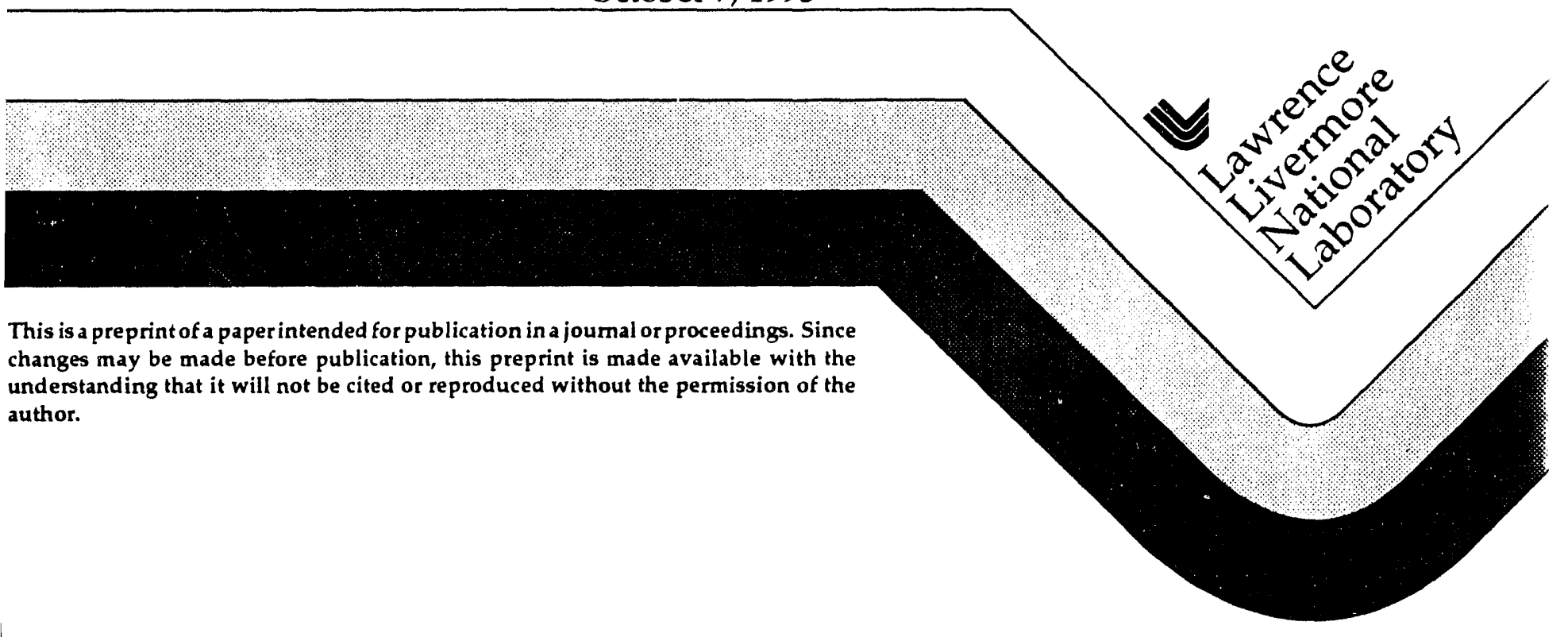

\section{MASTER}

OISTRIBUTION OF THIS OOCIIMENT IS UHLSATIII 


\section{DISCLAIMER}

This document was prepared as an account of work sponsored by an agency of the United States Government. Nejther the United States Government nor the University of California nor any of their employees, makes any warranty, express or implied, or assumes any legal liability or responsibility for the accuracy, completeness, or usefulness of any information, apparatus, produch, or process disclosed, or represents that its use would not infringe privalely owned rights. Reference herein to any specific commercial products, process, or service by trade name, trademark, manufacturer, or otherwise, does not necessarily constitute or imply its endorsement, recommendation, or favoring by the United States Government or the University of California. The views and opinions of authors expressed herein do not necessarily state or reflect those of the United States Govermment or the Cniversity of California, and shall not be used for advertising or product endorsement purposes. 


\title{
EVALUATION OF THE ATMOSPHERIC RELEASE ADVISORY CAPABILITY EMERGENCY RESPONSE MODEL FOR EXPLOSIVE SOURCES
}

\author{
Ronald L. Baskett, Robert P. Freis, and John S. Nasstrom \\ EG\&G Energy Measurements, Inc. \\ P. O. Box 8051 \\ Pleasanton, CA 94588 USA
}

\section{INTRODUCTION}

The Atmospheric Release Advisory Capability (ARAC) at the Lawrence Livermore National Laboratory (LLNL) uses a modeling system to calculate the impact of accidental radiological or toxic releases to the atmosphere anywhere in the world (Sullivan et al., 1993). Operated for the U. S. Departments of Energy and Defense, ARAC has responded to over 60 incidents in the past 18 years, and conducts over 100 exercises each year. Explosions are one of the most common mechanisms by which toxic particulates are injected into the atmosphere during accidents. Automated algorithms with default assumptions have been developed to estimate the source geometry and the amount of toxic material aerosolized. The paper exam-ines the sensitivity of ARAC's dispersion model to the range of input values for explosive sources, and analyzes the model's accuracy using two field measurement programs.

\section{MATHEW/ADPIC MODELING SYSTEM}

ARAC's emergency response computer system is built around the MATHEW (mass-consistent three-dimensional wind field) and ADPIC (atmospheric dispersion particle-in-cell) diagnostic models (Sherman, 1978, Lange, 1978). These models are run on a three-dimensional Eulerian grid typically with $40 \times 40 \times 14$ uniform rectangular cells scaled to encompass the desired domain. Wind speed and direction from up to 50 surface stations and 15 upper-air profiles within and surrounding the domain are used to initialize MATHEW. Surface data are first interpolated using inverse-distance-squared weighting of the input data. MATHEW then minimizes the divergence in the initialized field based on the continuity equation. Vertical motions are created and horizontal motions are adjusted according to the effects of atmospheric stability and terrain.

ADPIC simulates atmospheric releases by partitioning the mass or radioactivity of the source material into thousands of Lagrangian "marker" particles. A diffusivity velocity is determined for each cell from the concentration gradient based on K-theory and similarity scaling relationships for the boundary layer. Assuming incompressibility, ADPIC then computes three-dimensional "pseudo-velocities" from the sum of the advection and diffusivity velocities at each cell corner. A particle's total vertical velocity is the sum of its pseudo-velocity interpolated to its position in the cell, its gravitational 
settling velocity, and its dry deposition velocity. Deposition velocities are applied in the lowest model layer (surface layer). For each time step, the Lagrangian marker particles are moved in three dimensions on the Eulerian grid according to their total local vertical velocities and their horizontal pseudo-velocities. Four inner nested grids, each with half the previous grid dimension, provide detailed resolution near the source.

\section{EXPLOSIVE SOURCE SIMULATION}

\section{Aerosolized Fraction and Particle Size}

If surrounded by explosive charge, the toxic source material is assumed to be completely aerosolized. State changes or chemical reactions in the high-temperature, high-pressure explosive environment are not modeled. Instead, we begin with a stabilized particle size distribution (PSD) of the source material after the condensation of detonation products. PSDs depend on the chemical and physical structure of the source material and can vary dramatically. Each source is parameterized with single or multiple log-normal PSDs. For heavy elements, the median aerodynamic diameter (MAD) is typically $20-40$ $\mu \mathrm{m}$, while the MAD for lighter elements is usually $1 \mu \mathrm{m}$ or less. As a rule of thumb when calculating the inhalation of the toxic material, $20 \%$ of heavy metal or transuranic element source mass and 90 to $100 \%$ of light metal or powder sources are in the respirable size range $(<10 \mu \mathrm{m} \mathrm{MAD})$.

\section{Static-Source Geometry}

Two methods are used to initialize the size and shape of the explosive cloud in ADPIC. The simplest of these is an empirical relationship fit to data from measured highexplosive (HE) detonations. Figure 1 illustrates the mushroom-shaped geometry characteristic of a cloud that stabilized a few minutes after a ground-level detonation. Particulate clouds were tracked by flash photography and theodolites for 22 evening and nighttime explosions during the May to June, 1963 Project Roller Coaster at the Tonopah Test Range, Nevada (Church, 1969). The measurement technique was considered accurate to within 20\%. The cloud top heights began to stabilize about 2 to 3 min after detonation during stable lapse rate conditions but did not stabilize within the 5-min tracking period when the temperature soundings were mostly adiabatic. Since cloud heights were only available at 2 min after detonation for all 22 experiments, only measurements at $2 \mathrm{~min}$ were used to establish the relationship to explosive amount. Based on a theoretical 1/4 power-law form, regression analysis produced the following equation using TNT-equivalent masses ranging from 54 to $1020 \mathrm{~kg}$ :

$$
\mathrm{H}_{\mathrm{t}}=92.6 \mathrm{M}_{\mathrm{TNT}}^{1 / 4}
$$

where $H_{t}=$ cloud top height $(m)$ at 2 min after detonation, and

$\mathrm{M}_{\mathrm{TNT}}=$ mass $(\mathrm{kg})$ of TNT-equivalent explosive. 


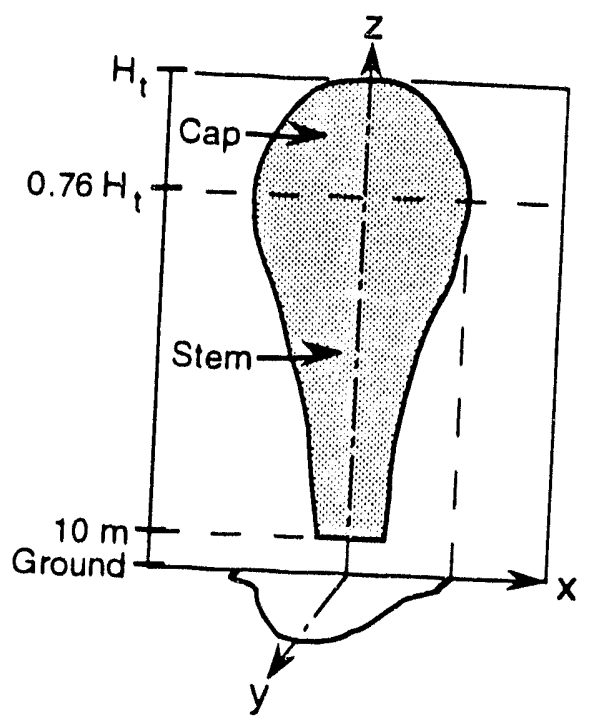

Figure 1. Static-source geometry for explosive cloud.

The three-dimensional static-cloud geometry is specified by assuming symmetry and employing truncated Gaussian particle cross-section distributions on the vertical and for the bottom or stem portion, half-Gaussians, one for the top or cap cloud and another visual observations at $2 \mathrm{~min}$ after deto to initialize the distribution of particles. Based on stem.

based on limited Roller with a median aerodynamic diameter particle measurements. For transuranic elements $24 \%$ in the cap cloud. For lighter elements $\mu \mathrm{m}, 76 \%$ of the mass was in the stem and cap cloud 2 min after detonation. While de or powders, the majority of the mass is in the static-source geometry may be somewhat subjing the source distribution values for the it uses a minimal amount of computer tim subjective, an advantage of this method is that ADPIC.

\section{Time-Dependent Explosive Cloud Rise} A more sophisticated method of simulating explosive cloud rise in a numerical
dispersion model involves calculating the time-dependent evolution of both physical and
thermodynamic properties of the high-explosive detontiol computer code developed of the high-explosive detonation. An explosive cloud rise ADPIC. Table 1 summarizes Boughton and DeLaurentis (1987) was implemented in DeLaurentis integrated the three-dimbodel inputs, physics and outputs. Boughton and and energy over the explosive cloud consional conservation equations of mass, momentum crossflow-induced pressure drag on the closs section. Included are entrainment and the of spherical symmetry reduces the integrat via empirical relationships. The assumption equations that produce the radius, centerline equations to a set of ordinary differential of the cloud each time step. 
Table 1. Summary of time-dependent explosive cloud rise submodel.

\begin{tabular}{|c|c|c|}
\hline INPUTS & PHYSICS & OUTPUTS \\
\hline Source amount & $\begin{array}{l}\text { Conservation Equations: } \\
\text { 1. Mass/water vapor }\end{array}$ & For the cloud: \\
\hline Source PSD & $\begin{array}{l}\text { 2. Momentum } \\
\text { 3. Thermal energy }\end{array}$ & 1. Radius \\
\hline Sounding (temperature, wind) & Assumptions: & 2. Height \\
\hline $\begin{array}{l}\text { Relative humidity } \\
\text { Surface roughness }\end{array}$ & $\begin{array}{l}\text { 1. Cloud symmetry } \\
\text { 2. Uniform cloud } \\
\text { cross-section }\end{array}$ & $\begin{array}{l}\text { 3. Vertical } \\
\text { velocity } \\
\text { 4. Temperature }\end{array}$ \\
\hline $\begin{array}{l}\text { Surface pressure } \\
\text { Particle-cloud } \\
\text { coupling coefficient }\end{array}$ & $\begin{array}{l}\text { Parameterizations: } \\
\text { 1. Entrainment } \\
\text { 2. Pressure drag } \\
\text { 3. Particle-cloud coupling }\end{array}$ & 5. Density \\
\hline
\end{tabular}

The explosive cloud is a sphere of hot gas that rises, expands and cools. Initially the sphere contains dry air and water, either as vapor or liquid. For a surface detonation, the radius of the initial sphere of ambient air is equal to the distance at which the blast overpressure has decayed to one atmosphere. Particles are be distributed uniformly within the initial sphere with an initial radius, $R_{0}(m)$, based on the empirical relationship:

$$
\mathrm{R}_{\mathrm{o}}=3.2 \mathrm{M}_{\mathrm{TNT}}^{1 / 3}
$$

Figure 2 shows the velocity components affecting the cloud and particles. Buoyancy causes the cloud to simultaneously expand radially and rise vertically. However, the cap cloud rises vertically within the first few seconds at a faster rate than predicted by buoyancy alone. To account for the initial "bounce" after surface detonations, an initial cloud liftoff height was added as an input parameter to the model.

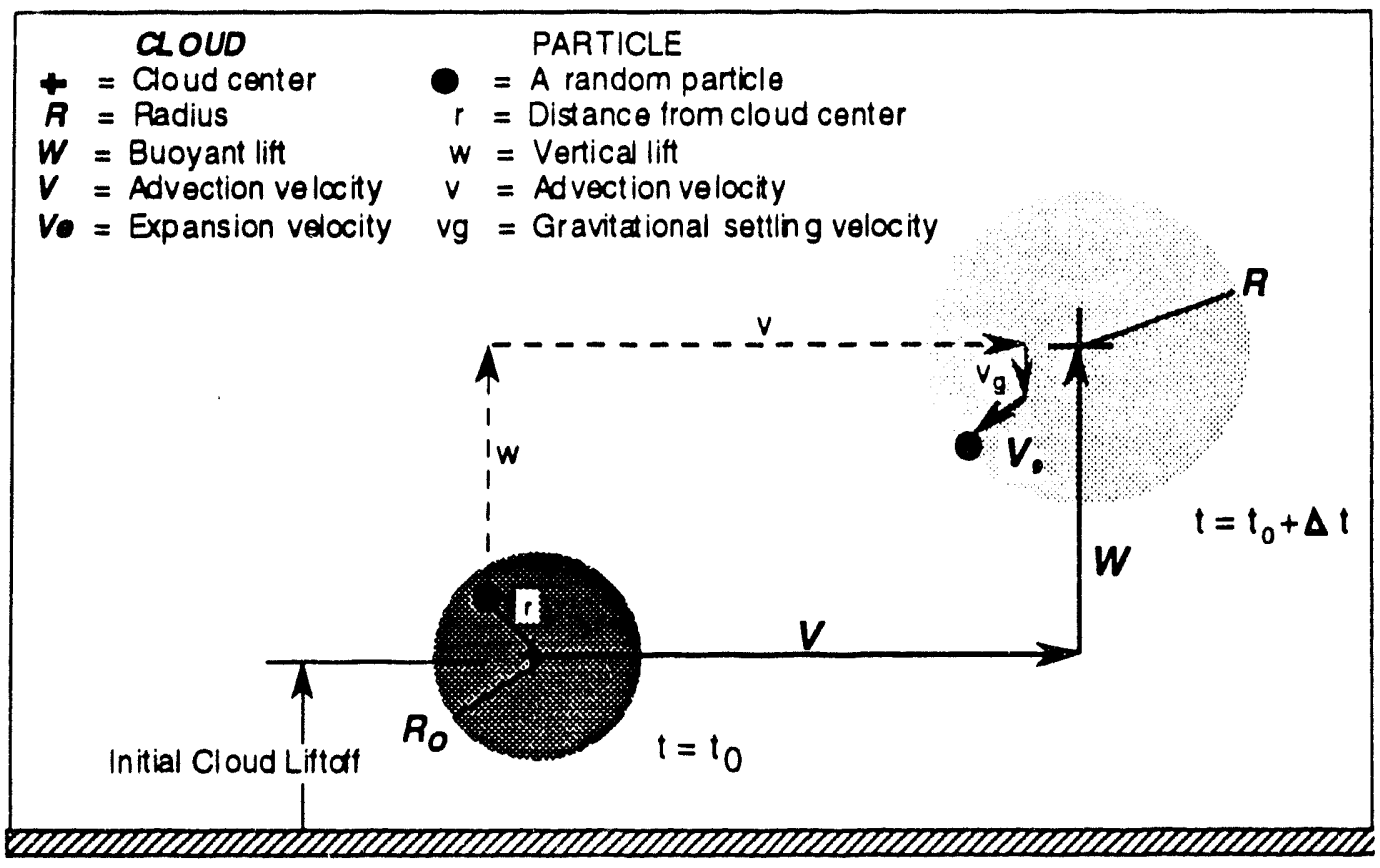

Figure 2. Time-dependent explosive cloud rise submodel. 
Particles in the explosive cloud are treated differently from those outside the cloud in two ways. First, particles in the cloud experience the radial expansion velocity of the cloud. Second, each cloud particle experiences a fraction of the cloud's vertical velocity due to its buoyant lift. Boughton and DeLaurentis (1987) parameterized the fraction of the cloud's vertical velocity that is transferred to each particle by the following relationship:

$$
w=W e^{-c\left(\frac{c}{R}\right)^{2}}
$$

where $w=$ the particle's vertical velocity $(\mathrm{m} / \mathrm{sec})$ due to the cloud's buoyancy,

$\mathrm{W}=$ the cloud's vertical buoyant velocity $(\mathrm{m} / \mathrm{sec})$,

$\mathrm{c}=$ the particle-cloud velocity coupling coefficient,

$r=$ the particle's distance $(m)$ from the cloud center, and

$\mathrm{R}=$ the cloud's radius $(\mathrm{m})$.

Expression (3) does not simulate the details of the toroidal evolution inside the cap cloud or entrainment of air around the cloud's edges. Instead, it provides a simple mechanism to approximate the overall size of the cloud and remove particles from its lower side. Particles at the center of the sphere can be lifted as much as the sphere, while those near the edge only receive a fraction of the cloud's vertical velocity. Each particle's vertical velocity depends on its position in the sphere and the coupling coefficient, a nondimensional empirically-derived model input parameter.

Figure 3 illustrates the difference between strong coupling $(c=0.1)$ and weak coupling $(\mathrm{c}=1.0)$ for large particles $(100 \mu \mathrm{m}$ MAD) one minute after a $23-\mathrm{kg}$ detonation. The explosive cloud rises over sloping terrain under neutral, $11 \mathrm{~m} / \mathrm{sec}$ winds moving from left to right. With strong coupling over half the particles are still within the confines of the spherical explosive puff. Weak coupling results in most of the particles leaving the explosive puffi and many depositing on the ground.

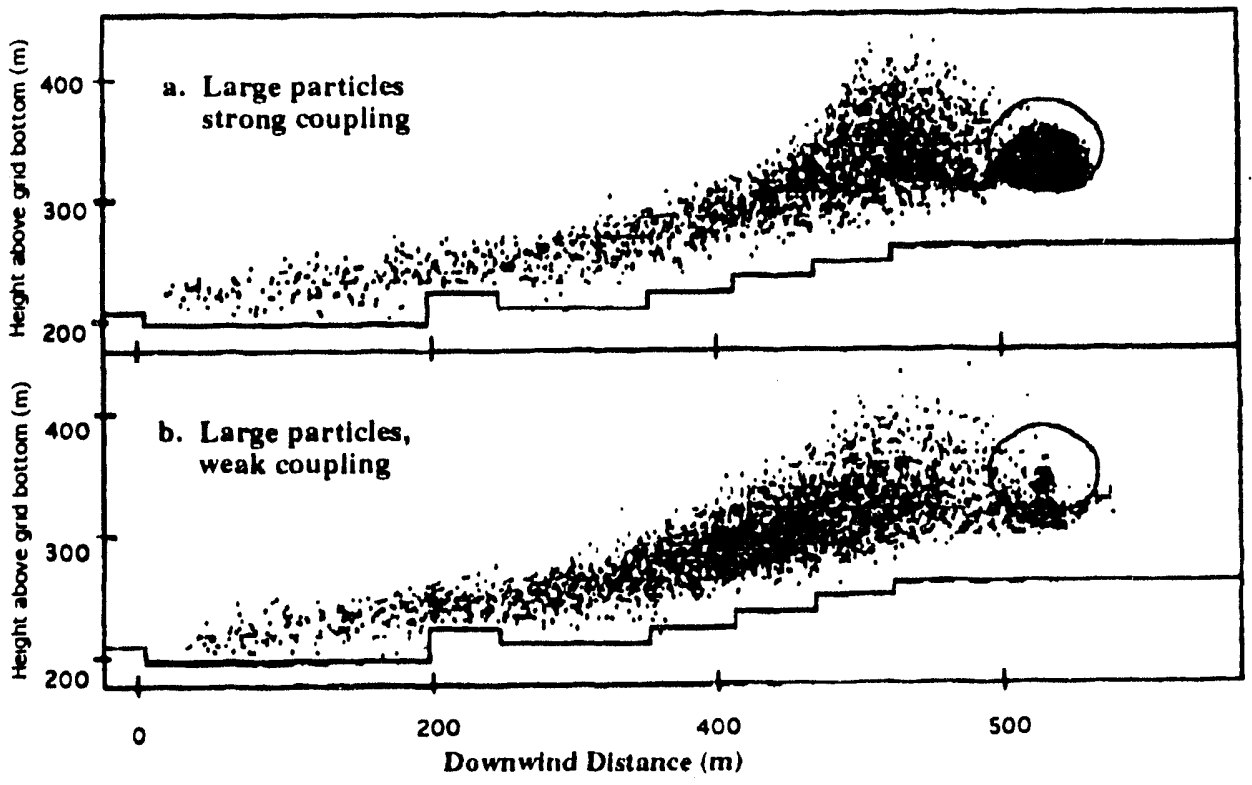

Figure 3. Effect of coupling coefficient on particle distribution one minute after detonation. 


\section{MODEL SENSITIVITY}

Because model inputs are not always well known in an accident, it is useful to know how sensitive the model results are to the inputs. Baskett and Cederwall (1991) tested the sensitivity of the static and time-dependent puff source methods to typical ranges of explosive mass, particle size and atmospheric stability. An example result is shown in Figure 4. For the typical range in explosive mass, the time-dependent cloud gives up to 10 times higher centerline concentrations near the source. This is because the timedependent model places more particles closer to the ground at small times compared to the vertical distributed particles in the static source. Beyond $2.5 \mathrm{~km}$, the time-dependent cloud produces about $35 \%$ less air concentration than the fixed cloud. This difference is caused by greater depletion and deposition of particles near the source in the timedependent method.

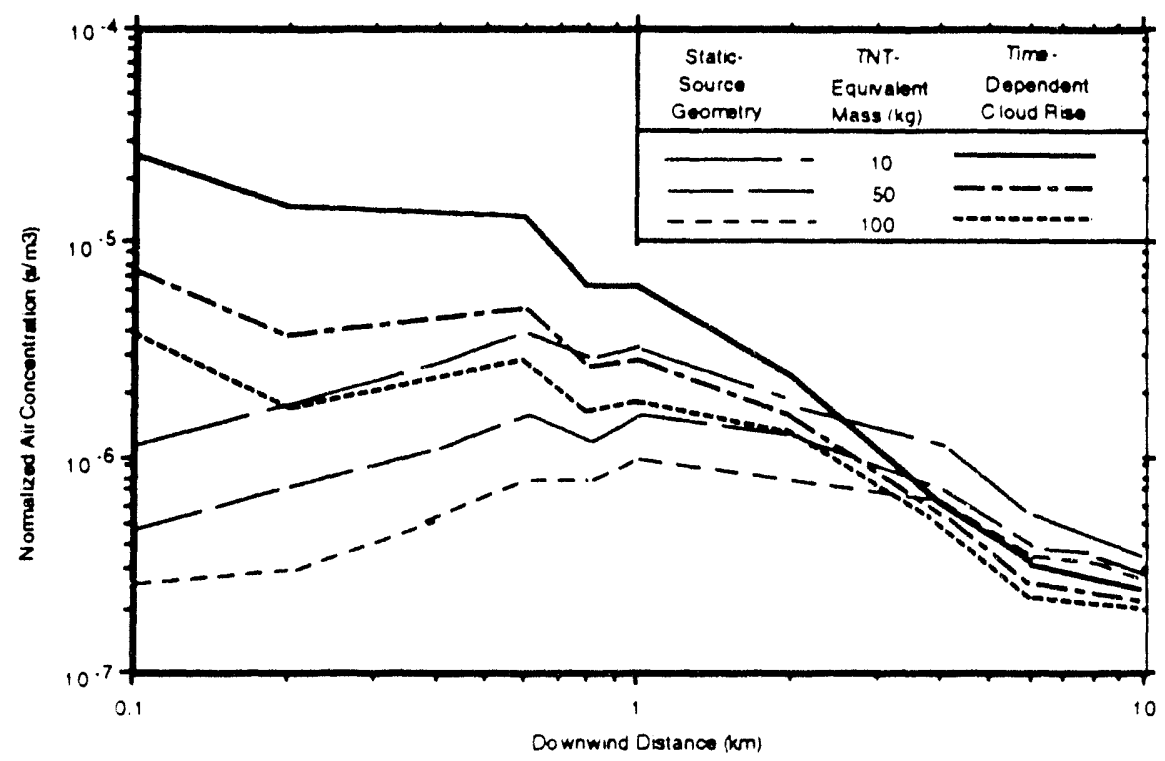

Figure 4. Sensitivity of static-source and time-dependent cloud rise to typical ranges of explosive mass.

\section{MODEL COMPARISONS WITH MEASUREMENTS}

\section{Source Model Comparisons}

Both static and time-dependent sources were tested against the Roller Coaster data. On the average, the static source produced cloud heights at 2 min within $20 \%$ of the observations for 22 detonations ranging from $54-1020 \mathrm{~kg} \mathrm{HE}$ during stable nighttime conditions. The time-dependent cloud top heights were compared with instantaneous observations 1 to $5 \mathrm{~min}$ after detonation for 15 Roller Coaster cases. The average difference of only $10 \%$ with almost no bias indicated a better agreement with the data than the static source. A coupling coefficient of 0.35 gave the best fit between the model and the observations.

The cloud top heights from the two source methods were also compared against observations of 6 smaller detonations $(6-31 \mathrm{~kg} \mathrm{HE})$ at LLNL's explosive test site during neutral to unstable daytime conditions. Figure 5 shows an example comparison for a 23$\mathrm{kg} \mathrm{HE}$ shot during $11 \mathrm{~m} / \mathrm{sec}$ winds. Comparisons between photographs and the model were made about every $10 \mathrm{sec}$ for the first $2 \mathrm{~min}$ after detonation. On the average for the 
6 detonations, the static source underestimated the 2 -min cloud top height by $12 \%$. The time-dependent model underpredicted the cloud top by $8 \%$ on the average, but nearly matched the observations when a 20-m initial liftoff was applied to 3 detonations. The shot configuration determined if there was an initial liftoff. A conservative assumption (one which produces higher ground-level concentrations) would be not to use any initial liftoff in the model.

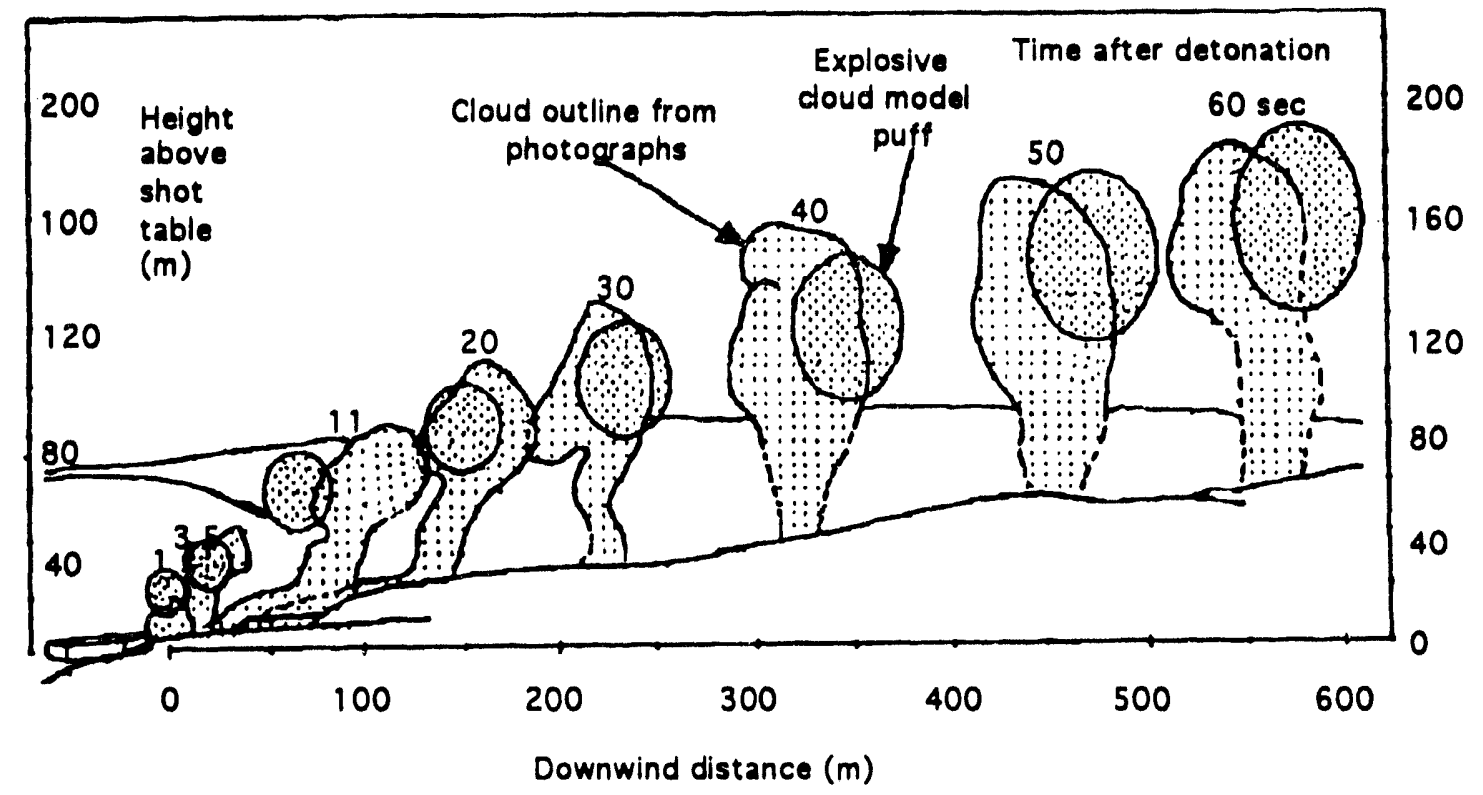

Figure 5. Comparison between cloud photography and time-dependent puff locations for a 23-kg detonation at LLNL's explosive test site.

\section{Dispersion Model Comparisons}

A limited number of air concentration and deposition measurements from the Roller Coaster experiments were also compared with the output from ADPIC. Figure 6 compares the static and dynamic source simulations with air concentration measurements of a $482-\mathrm{kg}$ TNT experiment. The puff traveled along a relatively flat valley floor $\mathrm{f}\urcorner \mathrm{r}$ the first $10 \mathrm{~km}$, and then it interacted with a ridge. The test occurred during $3-$ to $5-\mathrm{m} / \mathrm{sec}$ stable nightime conditions. Measurements of $40-\mu \mathrm{m}$-median diameter transuranic particles were made downwind. The plot shows a comparison along the computed plume centerline. Using the static source, ADPIC underestimates the centerline concentration for the first kilometer, does well for a few kilometers, but overestimates the measurement past $5 \mathrm{~km}$. Overall, the model better matches the observed data better using explosive cloud rise with $\mathrm{c}=0.35$. 


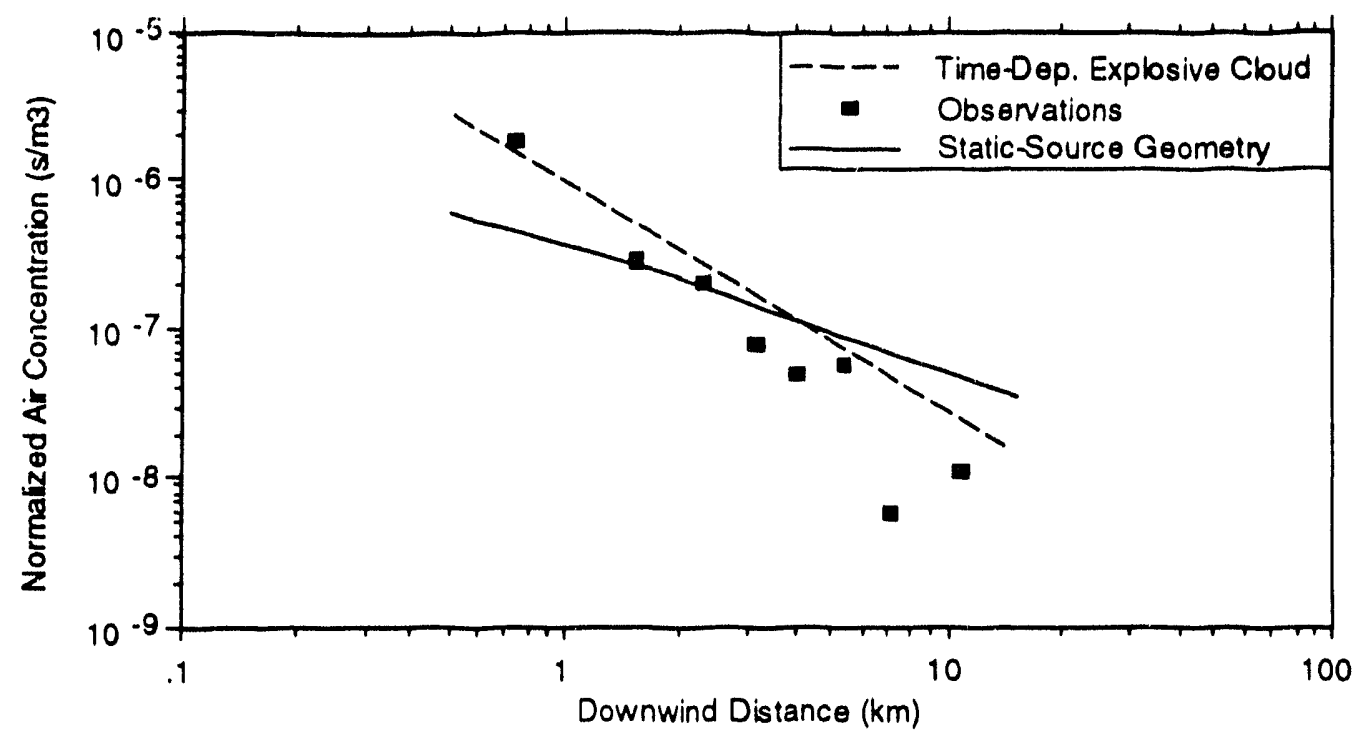

Figure 6. Comparison of downwind centerline particulate air concentrations with observations from a 482-kg detonation during Project Roller Coaster.

Figure 7 compares the observed deposition from the $23-\mathrm{kg}$ detonation containing light powder particles at LLNL's explosive test site. With 5\% of the source material as $100-\mu \mathrm{m}$ particles, a coupling coefficient of 1.0 produced values that were within a factor of 2 for the first $150 \mathrm{~m}$. Measurements further downwind distances were not available.

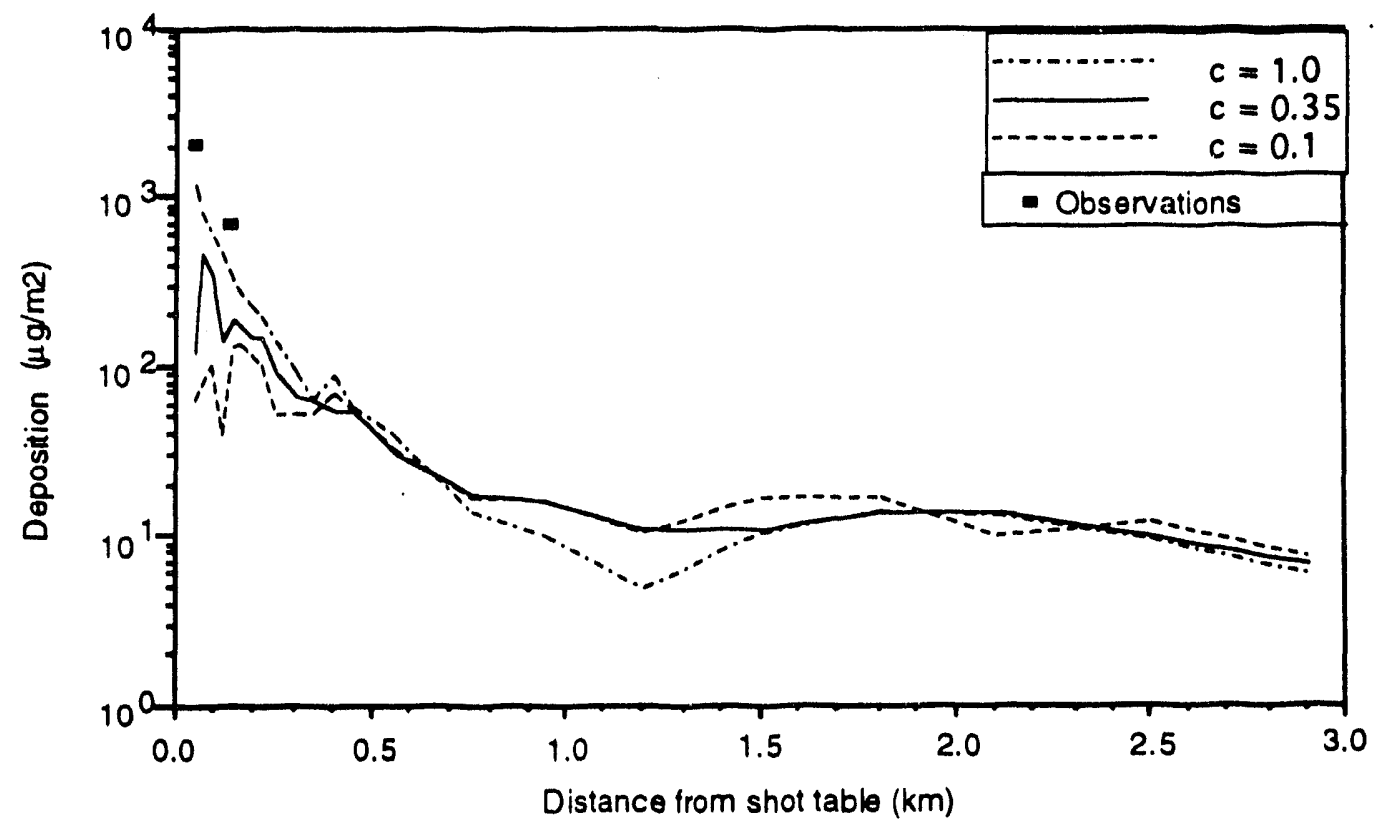

Figure 7. Comparison of downwind centerline deposition from the time-dependent cloud rise model with particulate observations from a $23-\mathrm{kg}$ detonation at LLNL's explosive test site. 


\section{CONCLUSIONS}

A great deal of uncertainty surrounds the characteristics of explosive sources within the framework of a three-dimensional diagnostic dispersion model. Even if the total source amount is known, the size distribution of the particles created by the detonation may not be well understood. A few field measurement programs have shed some light on how to reduce uncertainties when determining inputs for modeling the toxic material aerosolized in explosions. The cloud geometry can be simulated either by static or timedependent models. The explosive cloud can be simulated by both source models to within $20 \%$ of its observed height if the explosive mass and the ambient temperature profile are known. The detailed time-dependent explosive puff model provides greater accuracy within the first few kilometers. If the source amount and its particle size distribution are known, the time-dependent cloud rise simulation can reproduce concentrations to within a factor of 2 for the first few kilometers. However, more field experiments that accurately account for the source mass, the aerosolized fraction, and the source particulate size distribution and provide the time evolution of the cloud as well as downwind concentrations are needed to verify the accuracy of the dispersion model.

This work was performed under the auspices of the U.S. Department of Energy at Lawrence Livermore National Laboratory under contract number W-7405-Eng-48 and EG\&G contract number DE-AC0893NV11265. By acceptance of this article, the publisher and/or recipient acknowledges the U.S. Government's right to retain a nonexclusive, royalty-free license to any copyright covering this paper.

\section{REFERENCES}

Baskett, R.L. and R.T. Cederwall, 1991, Sensitivity of numerical dispersion modeling to explosive source parameters, Air \& Waste Management Association 84th Annual Meeting, Vancouver, BC. Paper 91-85.6.

Boughton, B.A. and J.M. DeLaurentis, 1987, An integral model of plume rise from high explosive detonations, 1987 ASME/AIChE National Heat Transfer Conference, Pittsburgh.

Church, H.W., 1969, Cloud rise from high-explosive detonations, SC-RR-68-903, Sandia National Laboratory, Health and Safety Report UC-41, Albuquerque.

Lange, R., 1978, A three-dimensional particle-in-cell model of the dispersal of atmospheric pollutants and its comparison to regional tracer studies, J. Appl. Meteor., 17:320.

Sherman, C.S., 1978, A mass-consistent model for wind fields over complex terrain, $J$. Appl. Meteor., 17:312.

Sullivan, T.S, J.S. Ellis, C. S. Foster, K.T. Foster, R.L. Baskett, J.S. Nasstrom, W.W.Schalk, 1993, Atmospheric Release Advisory Capability: Real-time modeling of airborne hazardous materials, accepted for publication, Bull. Amer. Meteor. Soc. 


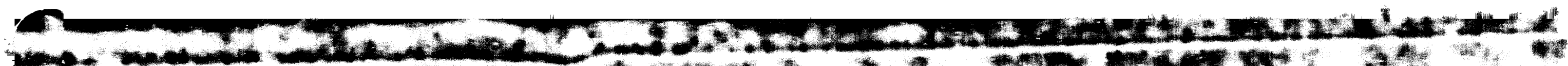

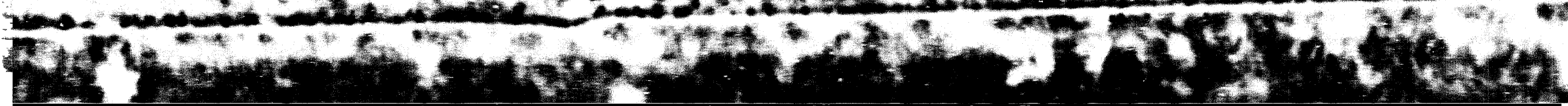
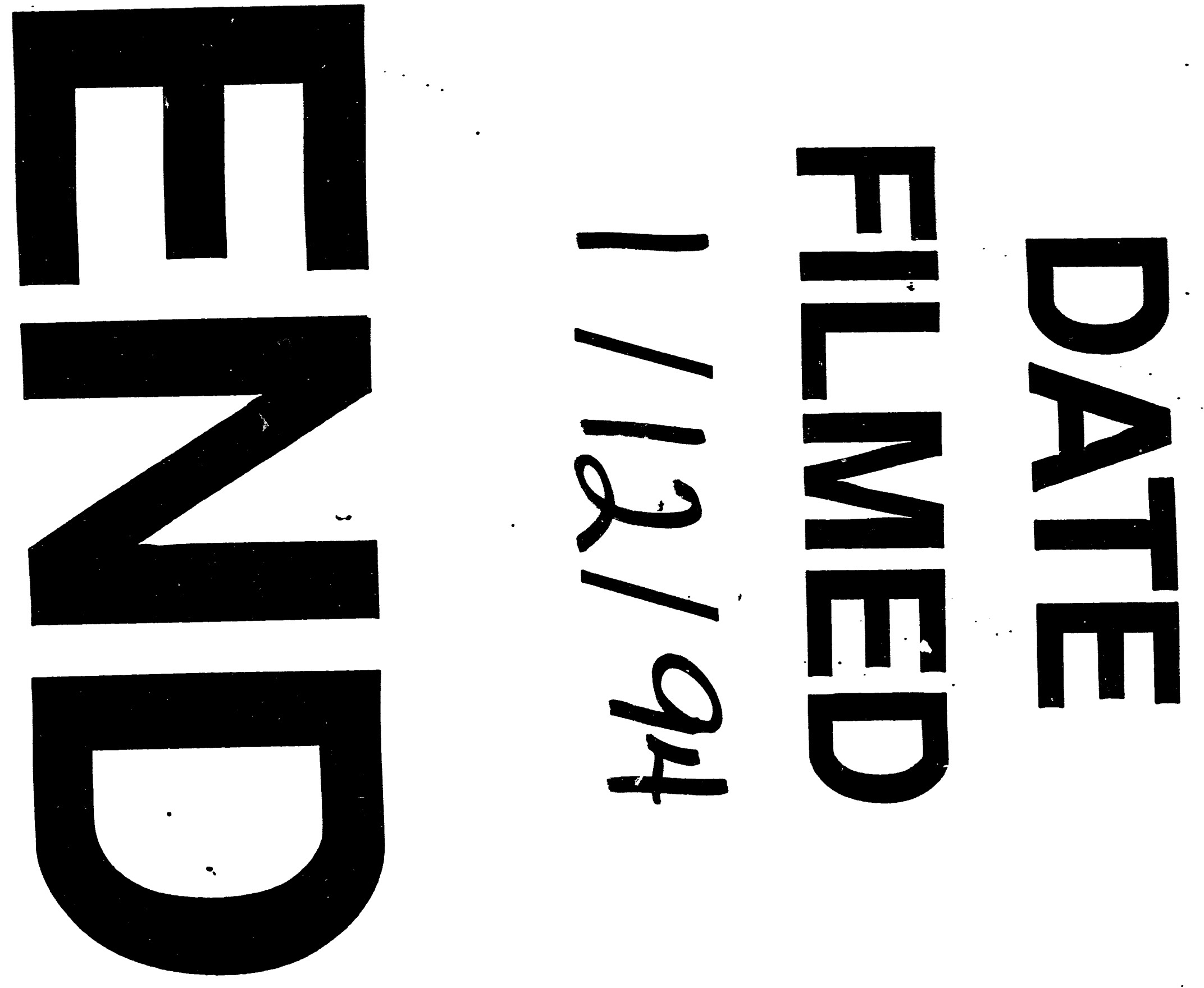
